\title{
E-Learning, Multiple Intelligences Theory (MI) And Learner-Centred Instruction: Adapting MI Learning Theoretical Principles To The Instruction Of Health And Safety To Construction Managers.
}

Paul McNamee, Multimedia Instructional Design, Ireland Dave Madden, Blended Learning Design, Ireland Frank McNamee, Multimedia Instructional Design, Ireland John Wall, Waterford Institute of Technology, Ireland Alan Hurst, Nottingham Trent University, United Kingdom Charalambos Vrasidas, CARDET - Intercollege, Cyprus Lucile Chanquoy, Universite de Nice Sophia-Antipolis, France Thierry Baccino, Universite de Nice Sophia-Antipolis, France Emrah Acar, Istanbul Technical University, Turkey Ela Önwy-Yazici, Istanbul Technical University, Turkey Ann Jordan, Waterford Institute of Technology, Ireland

\begin{abstract}
This paper describes an ongoing EU project concerned with developing an instructional design framework for virtual classes (VC) that is based on the theory of Multiple Intelligences (MI) (1983). The psychological theory of Multiple Intelligences (Gardner 1983) has received much credence within instructional design since its inception and has been implemented successfully in a wide array of traditional educational settings. Nonetheless, very little research has been carried out on developing frameworks for elevating MI into an e-learning environment. Specifically, the project hopes to adapt and utilize MI theoretical learning principles to create a virtual class specifically designed for instructing health and safety to construction managers. This paper explores the emerging principles from both theory and practice in order to identify the appropriate methodology for the successful incorporation of MI based instructional techniques in the virtual class design. Guidelines are provided on how the MI concept of 'entry points' can best be adapted for the specific learners (in this case construction managers) and class content (in this case health and safety). Of particular concern to this papers examination of 'entry points' is the potential for the deployment of intelligence profiling research to create a class tailor-made for construction managers while simultaneously adaptive to each learners individual needs. Emerging from this analysis, the paper will provide core recommendations including how to create problem based instructional activities that are directly related to both the participant's intelligence strengths and to the class content.
\end{abstract}

\section{INTRODUCTION}

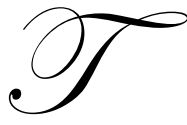

he Minerva Project is concerned with developing an instructional design framework for virtual classes (VC) that is based on the psychological theory of Multiple Intelligences (MI) introduced by Dr. Howard Gardner (Frames of Mind 1983). Specifically, the project aims to adapt and utilise MI theoretical learning principles to create a virtual class designed for instructing health and safety to construction professionals. MI theory has enjoyed widespread testing and implementation in the traditional classroom, with 
numerous reports of positive effects on learners, teachers, schools and parents (e.g. Chen et al, 1998). There is also much teacher instigated action research based on qualitative data reporting the positive effects of MI (e.g. Goodnough, 2001, Campbell 1991). Nevertheless, the effectiveness of MI within an e-learning environment has yet to be fully assessed. This project is being undertaken with a view to forming a reciprocal relationship between MI and e-learning that increases the potential for achieving learning objectives associated with both. This will involve exploiting the unique reach, scale and engagement value of the virtual environment to implement MI principles in a fashion that replicates the success associated with the traditional classroom, if not the methodology.

The innovative nature of the task means that a successful learning outcome will depend on a well researched and carefully implemented approach toward class design. As a result, the successful elevation of MI to an e-learning environment is being approached through an action research methodology designed to investigate, plan and trial the steps by which MI will be implemented. The goal of this paper is to explore some of the emerging principles regarding the methodology for the successful incorporation of MI based principles in the instruction of construction health and safety. Specifically, this will involve the identification of how the MI concept of 'entry points' can best be employed to target the specific learners (construction workers) and maximise learning outcome (health and safety). Of particular concern to this papers examination of 'entry points' is the potential for the deployment of intelligence profiling research to create a class 'tailor-made' for construction professionals while simultaneously adaptive to each learners individual needs.

\section{MULTIPLE INTELLIGENCES THEORY: AN OVERVIEW}

The theory of Multiple Intelligences (MI) was devised by Harvard University's Howard Gardner in his 1983 book Frames of Mind and it represents a significant departure from the traditional view of intelligence, as a single (and largely innate) capacity (often referred to as $g$ ). Instead it posits that intelligence is pluralistic with each individual possessing at least eight intelligences that are the reflection of the influences of inherited biology, environmental culture and life experiences (Gardner 1993). Typically, individuals display 'jagged' intelligence profiles with strength in one area not necessarily predicting strength in another area (Gardner 1993). These eight intelligences and there associated abilities are summarised in table 1 below.

\section{Multiple Intelligences As An Effective Pedagogy}

According to the theory of Multiple Intelligences, traditional learning environments tend to stimulate just two intelligences (logical mathematical and linguistic). Such environments are therefore less engaging to those high in other intelligences since each individual displays a unique profile. Considering this, it is not surprising that personalisation of learning is the key consideration of an MI approach that is based on engaging the learner through their own abilities and preferences. Learning that is informed by MI offers the possibility of a more inclusive pedagogy because it takes a wide view of intelligence and allows students to learn through their own varying intelligence strengths and not be marginalised by traditional ways of learning (Barrington 2004). Guild 1997 compared key principles of multiple intelligences, learning styles, and cognitive based education and concluded that these approaches intersect significantly in there learner centred approach and emphasis on designing curricula with depth and breadth. The MI approach is congruent with many contemporary theorists who have argued that in order to achieve optimum instruction; the learner should be profiled by learning need, learning style, intelligences and presentation preferences, in this way content and learner can then be uniquely matched (Reigeluth 1999).

\section{Multiple Intelligences And E-Learning}

The e-learning environment is an example of what Howard Gardner (1999) refers to as the "versatile technologies' that 'should eventually make it much easier to personalize education'. Gardner predicted as early as 1983 that "the potential utility of computers in the process of matching individuals to modes of instruction is substantial" and that "the computer can be vital facilitator in the actual process of instruction" (p391) With this goal in mind the Minerva project seeks to exploit the capabilities of the virtual class to implement the MI learning principle of 'entry points' and thereby ensure that class design targets the varying intelligences of the individual construction worker. A necessary first step to such a process is a thorough understanding of the theoretical basis for 
instructing through 'entry points' and to identify from the literature the methodology for class design which is most likely to be successful.

Table 1: Intelligences and related abilities Gardner (1993) Jordan (2003)

\begin{tabular}{|l|l|l|}
\hline \multicolumn{1}{|c|}{ Intelligence } & \multicolumn{1}{|c|}{\begin{tabular}{c} 
Associated abilities \\
\multicolumn{1}{|c|}{}
\end{tabular}} & $\begin{array}{c}\text { Professions exhibiting these } \\
\text { intelligences }\end{array}$ \\
\hline Linguistic & Capacity to use language to express and appreciate complex meanings & Poets, writers, storytellers. \\
\hline $\begin{array}{l}\text { Logical- } \\
\text { Mathematical }\end{array}$ & $\begin{array}{l}\text { Ability to use and appreciate abstract relations, carry out } \\
\text { inductive/deductive reasoning, numerical abilities. }\end{array}$ & $\begin{array}{l}\text { Scientists, Mathematicians, } \\
\text { Accountants }\end{array}$ \\
\hline Spatial & $\begin{array}{l}\text { Ability to perceive visual and spatial information, and to transform and } \\
\text { modify this information, and to recreate visual images }\end{array}$ & $\begin{array}{l}\text { Artists, architects, sculptors and } \\
\text { engineers }\end{array}$ \\
\hline $\begin{array}{l}\text { Bodily- } \\
\text { Kinaesthetic }\end{array}$ & $\begin{array}{l}\text { Use of all or part of one's body to solve problems, fashion products, or } \\
\text { construct meaning }\end{array}$ & athletes, surgeons, \\
\hline Musical & Create, communicate and understand meanings made out of sound & composers, opera singers \\
\hline Interpersonal & $\begin{array}{l}\text { Ability to perceive and make distinctions in the moods, intentions, } \\
\text { motivations and feelings of other people and to act accordingly }\end{array}$ & teachers, psychologists \\
\hline Intrapersonal & $\begin{array}{l}\text { Enables individuals to understand themselves and to draw on that } \\
\text { understanding to make decisions about viable courses of action }\end{array}$ & $\begin{array}{l}\text { No specific profession -Those } \\
\text { achieving high status }\end{array}$ \\
\hline Naturalist & Distinguish among, classify and use features of their environment & farmers, gardeners, botanists, \\
\hline
\end{tabular}

\section{What Are 'Entry Points'?}

Several years after Frames of Mind (1983) Gardner developed a framework based on MI for constructing a curriculum to support learners who display diverse strengths in each of the eight intelligences. Gardner outlined the important aspects of such a framework in the 1991 book The Unschooled Mind (summarised below in Table 2). The concept of 'entry points' is best envisaged as different doors, each mapping on to different intelligences. The 'entry points' which are more or less accessible depends on the intelligence profile of the learner, but what is important is that each of them leads to the topic being studied (Gardner 1991). Essentially, because the entry points are designed to target all the intelligences, if one instructs any given topic in this manner then nearly all students should find ways to get at the substance of the topic using their own varying strengths. For example, if a learner displayed a strong spatial intelligence and low levels of linguistic and logical-mathematical intelligence, they would be less likely to engage substantively with a typical history lesson based on the interpretation of descriptive accounts. Gardner outlines the way in which such a student could be engaged through an entry point which maps on to their intelligence strengths:

To students with high degrees of spatial intelligence, for example, the history of an era might best be introduced through art, architecture, and/or geography. For those students with high interpersonal or linguistic intelligences, biographies and dramatic re-enactments might prove better vehicles. (Blythe and Gardner 1990)

Therefore, in order to achieve a satisfactory learning outcome for all learners, the varied intelligence strengths of the individual learners should have a direct bearing on the methods of instruction. One of the key challenges facing the Minerva project is achieving this by identifying the most effective way to adapt and utilise the concept of entry points for the specific learners (construction professionals) and the content of the class (health and safety). An important step in achieving this is identifying the guidelines for using 'entry points' which have emerged from the literature as best practice.

\section{Guidelines For Instructing Through 'Entry Points'}

It is important to note that while the theoretical conceptualization of multiple intelligences and the entry points which relate to those intelligences is universal, the manner for implementing 'entry points' most effectively is heavily dependent upon the method of instruction, the learner and the requisite learning outcome, as Gardner puts it: 
The important pedagogical point is that any concept can be presented in more than one way, and everyone benefits when we have "multiple entry points" to the same idea, theory, concept, or framework. There is no point in prescribing how many ways to present an idea; that depends upon the idea, on the one hand, and one's own teaching styles and audience, on the other. (Gardner 1997)

Table 2: Entry points

Gardner (1991)

\begin{tabular}{|l|l|l|}
\hline \multicolumn{1}{|c|}{ Entry Point } & \multicolumn{1}{|c|}{ Description } & \multicolumn{1}{|c|}{ Example of instruction } \\
\hline Narrative & $\begin{array}{l}\text { The narrative entry point deals with the 'story' that is } \\
\text { central to the topic }\end{array}$ & $\begin{array}{l}\text { Case studies, narrative or themed } \\
\text { stories, descriptive accounts }\end{array}$ \\
\hline Logical Quantitative & $\begin{array}{l}\text { The numerical aspects of a topic, typically involves } \\
\text { deductive or logical reasoning that can often be captured by } \\
\text { if-then syllogisms }\end{array}$ & $\begin{array}{l}\text { Statistics, graphs, logic reasoning } \\
\text { tasks }\end{array}$ \\
\hline Aesthetic & $\begin{array}{l}\text { The aesthetic entry point engages artistic aspects of a topic. } \\
\text { It may also focus on sensory features associated with the } \\
\text { topic }\end{array}$ & $\begin{array}{l}\text { Three-dimensional } \\
\text { representations, images, videos, } \\
\text { design activities }\end{array}$ \\
\hline Experiential & $\begin{array}{l}\text { should provide students with an opportunity to engage with } \\
\text { the topic in a 'hands-on' manner }\end{array}$ & $\begin{array}{l}\text { Any 'Hands on' interaction with } \\
\text { the subject matter of the topic }\end{array}$ \\
\hline Interpersonal & $\begin{array}{l}\text { The interpersonal entry point involves working together } \\
\text { with others to learn about a topic }\end{array}$ & $\begin{array}{l}\text { Discussion forum, group problem } \\
\text { solving, perspective exchanging }\end{array}$ \\
\hline Existential/Foundational & $\begin{array}{l}\text { This entry point deals with fundamental, philosophical } \\
\text { questions about the nature of the topic, why it exists, and/or } \\
\text { what is its meaning. }\end{array}$ & $\begin{array}{l}\text { Any questioning of the foundation } \\
\text { or substance of a topic }\end{array}$ \\
\hline
\end{tabular}

Kornhaber, Fierros and Veenema (2004) investigated the methods employed by teachers to implement MI teaching principles and 'entry points' in the classroom. They found that the approaches adopted were extremely diverse; however the authors point out that those who reported success had most often adapted the principles both to their own instructional strengths and the topic being explored. The authors also point out that a common pitfall of educators attempting to implement MI occurs when they divide the curriculum up into seven or eight 'intelligence activities'.(P7) While this may provide a direct line from theory to implementation, it can nevertheless result in superficial activities that examine a topic along the breadth of the intelligences rather than the in-depth content of the topic. The authors underline the importance that a topic be examined through the entry points that 'map naturally' on to the topic itself:

It is important to strike a balance between always engaging a student through his or her strongest intelligences and tackling what's to be learned in a substantive way. We argue that the balance should be tilted to allow students strengths to be engaged substantively, rather than superficially, in the learning at hand. ( Kornhaber, Fierros and Veenema 2004)

Considering these recommendations for improving learning through MI, the Minerva project set the goal of adapting MI learning principles to the strongest intelligence strengths of its learners, to exploit the 'entry points' which map most naturally on to the content of the class and to utilize the instructional strengths of the virtual class.

\section{ADAPTING MI AND 'ENTRY POINTS' TO THE MINERVA PROJECT}

The professional nature of the learners in this case (construction managers) provides a natural basis for identifying the most relevant 'entry points' to be used in their instruction. Such professionals have already approached what Gardner refers to as 'end states' in the use of their strongest intelligences (Gardner 1993). In other words they have already shown some preference for an intelligence, been tested in that intelligence and most importantly they already commonly utilise the entry points associated with that intelligence in the daily environment of their profession. The process of instructing to a particular group of professionals is therefore conceptually different to instructing to a group of children with a diverse range of under-developed intelligence preferences. For example, while one could not assume that a logical-quantitative entry point would be effective for everybody if instructing a class at primary school age or indeed that any child would be likely to have a preference for logical- 
quantitative 'entry point'. On the other hand, if one is designing a class for instructing a group of accountants, it would be reasonable to assume that a logical quantitative entry point would be effective considering that strength and preference in the intelligence has already been displayed and most importantly, a logical quantitative 'entry point' is already commonly employed within their professional context. However, the project team did not wish to presume which intelligences and 'entry points' were more relevant and instead decided to carry out profiling on a sample of construction workers in order to determine the intelligence strengths which tend to be associated with the 'end state' of the construction manager. Essentially, if there are particular intelligences which emerge as more dominant amongst a group of construction managers, then these intelligences are likely to be ones particularly associated with their working environment. This is not least because the particular intelligence profiling being employed is designed upon the MI principle that the measure of one's proficiency in a particular intelligence is the ability to use it to solve problems and fashion products that are valued in a particular cultural setting or environment (Gardner, 1983). This is epitomized by those who have reached a professional 'end state' and commonly utilise the intelligence strengths necessary for their profession within their professional environment, as Gardner says:

Intelligences are always conceptualized and assessed in terms of their cultural manifestation in specific domains of endeavor and with reference to particular adult "end states." (Gardner 1989)

Therefore, the potential for identifying associated professional intelligence strengths and relevant 'entry points' for the 'endstate' of construction manager was approached as one means of providing learner centred instruction and maximising learning outcome.

The basis for this approach, however, was not alone built on the premise of identifying associative intelligence strengths. A key validation for this approach is also the opportunity for identifying the 'entry points' which map most naturally onto the content of the class (i.e. construction health and safety) as recommended by Kornhaber, Fierros and Veenema 2004 . This is particularly relevant to the Minerva class design considering that the learning objective and content of the virtual class is based on an issue (health and safety) situated within that specific context (i.e. the construction site). Accordingly, an understanding of the 'entry points' which are more relevant to the construction site allows the class design to focus on the 'entry points' which map most naturally on to the topic of health and safety within the construction site. This increases the likelihood of in-depth learning and prevents instruction from being based on superficial intelligence activities which bear no relation to the class content. To clarify, if the construction managers displayed a high mean in interpersonal intelligence, this would suggest that the professional construction environment was one in which interpersonal strengths are employed and that the construction profession represents one of the possible 'end states' of high interpersonal intelligence. Consequently, the class could then look to maximising learning by targeting the interpersonal entry point within an interpersonal health and safety context (e.g. a simulated conversation with a construction worker about health and safety). Furthermore, this need not occur at the exclusion of other 'entry points' found to be less relevant to the profession since it is essential that as many 'entry points' as possible are incorporated. For example, if linguistic intelligence was found to be less relevant, nevertheless, the instruction could be extended to include it, while maintaining the interpersonal context relevant to the profession (e.g. 'Narrative account of a simulated conversation with a construction worker explaining the logic for wearing a safety harness on a scaffold).

\section{PROFILING}

The goal of carrying out intelligence profiling was to establish the intelligence strengths associated with the 'end state' of the construction profession and thereby situate the activities of the class within health and safety contexts that related to the most relevant 'entry points'. It must be emphasised that the goal of this profiling was not to lay claim to identifying the universal characteristic of the individual construction worker but instead to identify the intelligences that tend to be relatively stronger for a group of professionals because of the very nature of their professional context. The important point is that an entry point chosen on the merit of its association with the learner and the learner's environment is relatively more useful for instructing a topic within that environment than one which bears little relation to either.

The Minerva team identified the MIDAS software for MI profiling developed by Dr. Branton Shearer as the ideal tool for profiling the construction managers based on the fact that it had already been utilised successfully 
for profession based profiles and career inventories (Shearer 2004, 2006) and is one of the very few MI profiling measures which have been praised by Howard Gardner (Gardner 1996) The MIDAS inventory consists of 93 questions and from the responses entered, a MI profile is generated for each participant. The MIDAS is an assessment that describes abilities in terms of strengths and weaknesses, however, scores are not like test scores because they not based on a comparison to other people.

Table 3: Strength of Individual Attributes

\begin{tabular}{|c|c|c|c|}
\hline & Mean & Std. Deviation & Related Intelligence \\
\hline School Mathematics & 72.71 & 22.32 & Logical-Mathematical \\
Spatial Awareness & 69.06 & 17.26 & Spatial \\
Report Writing & 68.39 & 16.32 & Linguistic \\
Spatial Problem Solving & 67.53 & 16.07 & Intrapersonal \\
Calculation & 65.06 & 17.00 & Logical- Mathematical \\
Social Persuasion & 63.96 & 20.53 & Interpersonal \\
Personal Knowledge / Efficacy & 63.84 & 14.54 & Intrapersonal \\
Effectiveness & 63.38 & 16.31 & Interpersonal \\
Problem solving & 63.33 & 19.77 & Logical Mathematical \\
Everyday Math & 61.31 & 17.14 & Logical Mathematical \\
Social Sensitivity & 58.65 & 22.16 & Interpersonal \\
Rhetorical Skill & 56.96 & 16.82 & Interpersonal \\
Working with Objects & 54.58 & 15.31 & Spatial \\
Natural Science & 54.13 & 20.96 & Naturalist \\
Artistic Design & 52.88 & 25.03 & Spatial \\
Strategy Games & 50.83 & 18.57 & Logical Mathematical \\
Expressive Sensitivity & 48.71 & 18.44 & Linguistic \\
Musical Appreciation & 47.02 & 17.97 & Musical \\
Athletics & 46.46 & 25.31 & Kinaesthetic \\
Plant care & 42.34 & 18.50 & Naturalist \\
Dexterity & 38.44 & 19.78 & Kinaesthetic \\
Animal Care & 35.12 & 20.42 & Naturalist \\
Vocal Ability & 29.37 & 24.16 & Musical \\
Composer & 21.56 & 17.67 & Musical \\
Instrumental Skill & 20.00 & 18.73 & Musical \\
\hline
\end{tabular}

Table 4: Overall strength in each intelligence

\begin{tabular}{|c|c|c|}
\hline & Mean & Std. Deviation \\
\hline Interpersonal & 63.42 & 11.66 \\
\hline Spatial & 60.20 & 16.40 \\
\hline Logical Mathematical & 59.39 & 14.84 \\
\hline Interpersonal & 58.84 & 17.28 \\
\hline Linguistic & 56.35 & 15.28 \\
\hline Naturalist & 44.20 & 17.28 \\
\hline Kinaesthetic & 42.51 & 16.15 \\
\hline Musical & 34.69 & 15.72 \\
\hline
\end{tabular}

\section{Midas MI Profiling of Construction Managers}

The sample consisted of forty construction managers who were approached to take part in the study through the partner universities. The participants were asked to fill out an extensive online questionnaire designed to access their intelligence strengths and preferences by examining responses to measures assessing the defining attributes of each intelligence. The data was then compiled into tables displaying the frequency with which each of these individual attributes were exhibited by the group (Table 3). These attributes were then sorted according to the intelligence with which they relate in order to provide an overall view of the descriptive statistics and relative strength of each of the eight intelligences within the sample. (Table 4) 


\section{DISCUSSION}

While the project team did not presume to know which intelligences would be strong within the construction context until the research was completed, it was unsurprising that high levels of spatial and logical mathematical emerged as central to the intelligence profile of the construction professionals, while musical and naturalist intelligences were found to be the least relevant. This is perhaps predictable considering that spatial and logical mathematical intelligence is central to the construction profession in general, where the ability to navigate the self and objects through space, to calculate measurements and angles, and to think three dimensionally are central to structural formation. Many elements of the construction environment contain a spatial and logical quantitative element; consequently, each of the professionals on the building site uses the 'entry point' associated with spatial relations within the construction environment. One obvious example is the reading of plans which involves the converting two dimensional images into three dimensional representations. This measures ability to visualize or form pictures of solid objects from looking at flat paper plans. Those who do well on this test can look at an architect's plans for a house or an engineers plan's for a bridge or machine and they can see the finished house or bridge or machine. That is they can see the finished product 'mentally' from various angles. Indeed, it could be argued that the reciprocal combination of logical-mathematical and spatial awareness has a unique interplay in the job of the construction professional where inductive and deductive reasoning and numerical skills are used to solve spatial problems. It should be regarded as best practice that the 'entry points' which are strong in both the learner and the profession and which map naturally onto the topic should be used to recreate the environment in which those skills will be used. The point, of course, is not to suggest that the resolution of all health and safety issues depends on logical-quantitative or spatial entry points, but rather that these are relevant 'entry points' to the environment and therefore should be utilised when recreating and instructing on a topic within that environment. On the other hand, musical or naturalist intelligence bears little or no relevance to this context, the intelligence strength of the learner or the content of the class and therefore a superficial inclusion of a naturalist based task at the expense of other tasks is considered to be unnecessary. While, bodily kinaesthetic skills are indeed associated with the construction site environment, the reason that this sample obtained such a low score may well be related to their professional status as managers. In any case, since the content of this class focuses on the instruction of identifying and dealing with health and safety problems, this does not map naturally onto any prominent kinaesthetic abilities and any attempt by the virtual class to tap into kinaesthetic instruction would be superficial rather than substantial. The low relevance of these elements appear to be further underlined by the fact that individual attributes relating to these three intelligences make up nine of the lowest ten scores in the table shown above. Considering the assertion of Kornhaber, Fierros and Veenema (2004) that the "balance should be tilted to allow students strengths to be engaged substantively, rather than superficially, in the learning at hand'. The inclusion of such elements would likely sacrifice substantive learning about the topic for the sake of instructing to unrelated intelligences. On the other hand, those attributes which have been shown to be particularly high are likely to be targeted during class design. For example, the particularly high scores of the participants in mathematics, spatial awareness, spatial problem solving, report writing and social persuasion are likely to be a key consideration for class design.

Intrapersonal intelligence achieved the highest mean of the individual intelligences and this intelligence tends to be displayed in those who have reached a professional or high performance status. It is associated with awareness of one's strengths and weaknesses and the ability to plan effectively to achieve personal goals (Gardner 1993). It involves taking responsibility for using understanding of one's own knowledge in making decisions. It is therefore important for situating a class activity within a health and safety setting that involves monitoring one's knowledge, thoughts and feelings and using them for solving problems and anticipating reactions to future courses of action (Jordan 2003). Accordingly, it can be useful for framing the learners mind within each individual learning activity, for example, getting the learner to focus on what personal goal they wish to achieve from the instruction, what strengths they anticipate they will use in the resolution of a health and safety problem, and reflect on what course of action they would take in order to resolve that problem. It is also worth noting that the highest intrapersonal intelligences in the subscales were very closely related with spatial and logical mathematical intelligences. For example, The highest scoring is 'spatial problem solving' which relates to a self awareness that involves the ability to solve problems by moving self and objects through space, this will be a clear consideration of the class design that employs spatial representations.

Interpersonal intelligence is the next highest on the scale and while it may not be directly associated with the construction site environment, it is very relevant for those in a management position or those charged with 
ensuring the health and safety of others. The ability to communicate effectively with others is paramount to ensuring that they comply with the health and safety directions in which they are instructed. The developed class will contain substantial interpersonal elements where learners will have an opportunity to interact with each other on topics surrounding the class content (e.g. discussion threads).

\section{Best Practice for the Integration of MI profiling and entry points into class design}

It is expected that the developed class will primarily focus on Intrapersonal, spatial, logical-mathematical and interpersonal intelligences that have been established as not only strong in the learners, but are also relevant to the professional context and thereby mapping naturally on to the requisite learning outcome of the class. It is recommended as best practice that the 'problem based' activities of the class be situated within health and safety construction site contexts with elements of these intelligences that and are solved by the construction managers ability to show a knowledge and competence in the intelligences related (intrapersonal) Consequently, the construction worker is engaged not merely through the strongest 'entry points' of their individual intelligences, but also through the opportunity to use these intelligences within their natural context to solve health and safety issues. A study by Kallenbach and Viens (2004) which examined the most successful approach to implementing MI based instruction found that instructors MI efforts paid off with high levels of student engagement and authentic instruction when they related directly to students' experiences and realities.

Of all the lessons...documented, those most favored by students and noted by teachers for high student engagement had content reflecting student interests and realities. Lessons that offered an authentic audience and an opportunity for students to apply activities to make real-life improvements were seen as best of all. (Kallenbach and Viens 2004, p. 62)

On the other hand, the authors report that for those topics that were not grounded in students' environments, MI made instruction more meaningful and relevant because students could approach activities from their preferred and strongest intelligences (p. 63) In the Minerva class a unique opportunity exists for amalgamating both of these successful principles by combining the construction professionals strongest intelligences with the context to which these intelligences apply in order to instruct on a topic within that context.

Nevertheless, It must be stressed that this is seen as the means for maximising learner engagement and that the class at all times will strive to incorporate as many 'entry points' as possible within each learning activity (e.g. case studies and descriptive accounts targeted at narrative 'entry point' and interactive elements aimed at experiential entry point). Within the developed class, content will be selected thematically that explores key health and safety concepts that are relevant to the environment and to the needs of the learner. This is in accordance with the recommendation that any instruction based on MI principles should be multifaceted and interactive with problem-based instructional approaches centered on the needs of the individual learner (Gardner, 1993 \& 1999; Kornhaber \& Krechevsky, 1995)

To help clarify the anticipated approach to problem based activities one example will be provided using storyboards already completed by the team and will be considered in light of the results of the strongest intelligences from the profiling subscales.

\section{SETTING THE CONTEXT - MIDAS PROFILING, ENTRY POINTS AND CLASS DESIGN}

Overall spatial ability was one of the highest scoring intelligences amongst the sample of construction managers $(M=60.2, S D=16.40)$. Related to this intelligence spatial awareness $(M=69.06, S D=17.26)$ and spatial problem solving $(\mathrm{M}=63.33, \mathrm{SD}=19.77)$ were shown to be particularly strong attributes and both refer to the ability to solve problems of spatial orientation and moving objects through space. The first step in creating a class activity to target these construction related abilities is to establish a spatial context. Campbell, Campbell and Dickinson (2003) suggest the means by which to target the spatial skills of a population should begin with establishing a visual environment. Those with high abilities in this intelligence are capable of learning by seeing and observing and respond highly to such media's as three dimensional representations, pictures and videos. Therefore, in this case, the potential exists to utilise the visual capabilities of the virtual class to create an interactive spatial environment that 
relates specifically to the use of spatial awareness and spatial problem solving to solve a health and safety based problem within a construction context. When designing an interactive spatial environment one should consider how to implement the characteristics associated with visual intelligence, these include:

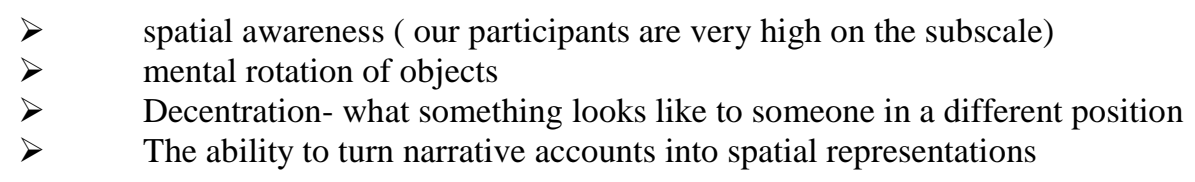

This places the learning within a spatial context; however this does not mean that other 'entry points' can not be utilised within this spatial context. For example, a narrative account or case study could accompany this spatial representation which describes a construction manager undertaking health and safety duties. The task could then involve an interactive element such as identifying the health and safety concern which the manager should have been capable of observing from different perspectives (spatial, logical-quantitative, and experiential). Once this hazard had been identified, a 3D image or real life picture of the hazard could be portrayed which placed the learner looking from the perspective of the manager on the hazard (experiential, spatial). An opportunity could then ensue for a discussion on the dangers of the hazard and how it could be resolved through the discussion forum (spatial, logical-quantitative, interpersonal, and experiential) or a questioning of the need for any health and safety training within this context (foundational). This could be then followed by the task of writing a report to the construction manager on what had been witnessed (narrative). The application of the intelligence could be tested by requesting participants to keep journal entries on the health and safety issues they observe at work which are related to what they have learned in class (narrative, experiential) This example is not designed to be prescriptive nor is the point to suggest that all instruction should be placed within a spatial environment but rather that problem based activities can be placed within contexts that map naturally on to the intelligences strengths of the professionals, the professional environment and the content of the class while still targeting each of the 'entry points'. This is the approach most likely to be effective for interactive problem based elements of the class and is a useful means for incorporating MI intelligence profiling and 'entry points' in a way that is adapted specifically to the needs of the learner and designed to maximise learning outcome.

\section{CONCLUSION}

MI theory is a definition and conceptualization of human intelligence. It is not and does not prescribe a particular approach or set of activities. Instead, MI theory offers a specific pluralistic conceptualization of intelligence that suggests that in order for instruction to be effective it must be approached through a number of 'entry points' that are capable of appealing to the intelligence strengths of the learner. The importance of using 'entry points' which map naturally on to the content of the topic was identified as crucial in ensuring substantive learning. It is the responsibility of each instructor to identify the most effective way of adapting the MI principles to match the intelligence strengths of the learner with the topic of instruction in order to maximize learning outcome. This paper has been concerned with identifying one such way that this can be achieved in the instruction of health and safety to construction professionals. The professional nature of the learning group was identified as a natural basis for targeting and exploiting the 'entry points' most relevant to the construction professionals, the environment of their profession and their relation to the learning outcome. Since the content of the class is to be based within the construction context, it is clear that such strengths associated with this context and the learner (i.e. construction professional) map naturally on to the improvement of a skill within that context (i.e. health and safety). Intelligence profiling revealed that spatial awareness, logical quantitative abilities and to a lesser extent interpersonal and intrapersonal intelligences represent such 'context intelligences' and could be relevant to many elements related to the topic. Therefore, it was identified as best practice that the problem based activities of the class should be situated within health and safety construction site contexts that are represented through spatial, logical quantitative, or interpersonal media and based on problems designed to target all of the 'entry points'. These problems should be solved by the construction professionals ability to show a knowledge and competence in the intelligence related. The ability of the e-learning environment to create visually rich and experiential environments which target each of these context intelligences is also highlighted and an example is provided of how one such spatial environment could be created while still targeting all of the entry points. 


\section{ACKNOWLEDGEMENTS}

As part of the EU-funded project: Multiple Intelligences Instructional Design Framework for Virtual Classes (228995 - CP -1-2006-1- IE - MINERVA - MPP).

\section{REFERENCES}

1. Barrington, Ernie. "Teaching to Student Diversity in Higher Education: How Multiple Intelligences Theory can help." Teaching in Higher Education, 9 (2004)

2. $\quad$ Blythe, Tina, and Howard Gardner. "A School for All Intelligences." Educational Leadership 47 (1990)

3. $\quad$ Campbell, Bruce. "Multiple Intelligences in the Classroom." In Context. 1991. 28 July 2007

$<$ http://www.context.org/ICLIB/IC27/Campbell.htm>.

4. Campbell, L., Campbell, B., \& Dickinson, D. Teaching and learning through multiple intelligences_(3rd Ed.). Boston, MA: Pearson Education, Inc (2004).

5. Chen, J., Krechevsky, M., \& Viens, J Building on children's strengths: The Project Spectrum experience. New York: Teachers College Press. (1998).

6. Gardner, Howard. 'Multiple Intelligences Go to School: Educational Implications of the Theory of Multiple Intelligences'. Educational Researcher_(18), 8. 1989.

7. Gardner, Howard. Frames of Mind: Theory of Multiple Intelligences. 2nd ed. London: Fontana, 1993

8. Gardner, Howard. The Unschooled Mind: What Children Think and How Schools Should Teach. New York: BasicBooks, 1991

9. Gardner, Howard. 'Multiple Intelligences as a Partner in School Improvement' Educational Leadership (55) 1997

10. Gardner, Howard, and Simon Hanson. "A Conversation with Howard Gardner." Brainconnection.Com. 1997. Scientific Learning Corporation. Accessed 05 Aug. 2007

〈http://www.brainconnection.com/topics/printindex.php3?main=conv/gardner>.

11. Gardner, Howard. "Foreword." Multiple Intelligences Research and Consulting Inc. 1996. Accessed 03 Aug. $2007<$ http://www.miresearch.org/>.

12. Goodnough, K. (2001), Multiple Intelligences Theory: a framework for personalizing science curricula, School Science and Mathematics, Vol. 101, Issue 4, p180.

13. Haley, M.H. (2004), Learner-Centred Instruction and the Theory of Multiple Intelligences with Second Language Learners, Teachers College Record, Vol. 106, Issue 1, p163.

14. Harvey, B, and D Beards. "E-Learning in Scottish Further and Higher Education." Education and Training 46 (2004): 353-360.

15. Kornhaber, M., \& Krechevsky, M. (1995). Expanding definitions of teaching and learning: Notes from the MI underground. In P. Cookson \& B. Schneider (Eds.), Transforming Schools. New York: Garland Publishers

16. Kornhaber, M.L., Fierros, E.G., \& Veenema, S. (2004). Multiple Intelligences: Best Ideas from Research and Practice. Needham Heights, MA: Allyn \& Bacon Publishers

17. Mettatal, G., Jordan, C.A. and Harper, S.M. (1997), Attitudes towards a multiple intelligences curriculum, Journal of Educational Research, Vol. 9, Issue 2.

18. Reigeluth, C. ed. (1999) Instructional-Design Theories and Models A New Paradigm of Instructional Design. Volume 2. USA. Lawrence Erlbaum Inc.

19. Shearer, C.B. (2004). Criterion related validity of the MIDAS scales. Retrieved 05-08-07 from www.MIResearch.org/research.php.

20. Shearer, C. B. (2006a). Exploring the relationship between intrapersonal intelligence and university students' career decision making, retention and academic success. Retrieved 05-08-07 from www.MIResearch.org/research.php .

21. Shearer, C.B. (2007) Multiple Intelligences Theory and Career Counseling: Exploring the Application of Multiple Intelligences to Career Counseling. Retrieved 05-08-07 from www.MIResearch.org/research.php 